\title{
Use of Nondestructive Testing of Ultrasound and Artificial Neural Networks to Estimate Compressive Strength of Concrete
}

\author{
Fernando A. N. Silva ${ }^{1}$, João M. P. Q. Delgado ${ }^{2, *}{ }^{\circledR}$, Rosely S. Cavalcanti ${ }^{1}$, António C. Azevedo ${ }^{2}{ }^{\mathbb{D}}$, \\ Ana S. Guimarães ${ }^{2}$ and Antonio G. B. Lima ${ }^{3}$ \\ 1 Departamento de Engenharia Civil, Universidade Católica de Pernambuco, Recife PE 50050-900, Brazil; \\ fernando.nogueira@unicap.br (F.A.N.S.); rosely.cavalcanti@hotmail.com (R.S.C.) \\ 2 CONSTRUCT-LFC, Department of Civil Engineering, Faculty of Engineering, University of Porto, \\ 4200-465 Porto, Portugal; antonio.costaazevedo@fe.up.pt (A.C.A.); anasofia@fe.up.pt (A.S.G.) \\ 3 Department of Mechanical Engineering, Federal University of Campina Grande, \\ Campina Grande 58429-900, Brazil; antonio.gilson@ufcg.edu.br \\ * Correspondence: jdelgado@fe.up.pt; Tel.: +351-225081404
}

Citation: Silva, F.A.N.; Delgado, J.M.P.Q.; Cavalcanti, R.S.; Azevedo, A.C.; Guimarães, A.S.; Lima, A.G.B Use of Nondestructive Testing of Ultrasound and Artificial Neural Networks to Estimate Compressive Strength of Concrete. Buildings 2021, 11, 44. https://doi.org/10.3390/ buildings11020044

Academic Editor: Giuseppina Uva Received: 29 December 2020

Accepted: 21 January 2021

Published: 27 January 2021

Publisher's Note: MDPI stays neutral with regard to jurisdictional claims in published maps and institutional affiliations.

Copyright: (c) 2021 by the authors. Licensee MDPI, Basel, Switzerland. This article is an open access article distributed under the terms and conditions of the Creative Commons Attribution (CC BY) license (https:// creativecommons.org/licenses/by/ $4.0 /)$.

\begin{abstract}
The work presents the results of an experimental campaign carried out on concrete elements in order to investigate the potential of using artificial neural networks (ANNs) to estimate the compressive strength based on relevant parameters, such as the water-cement ratio, aggregatecement ratio, age of testing, and percentage cement/metakaolin ratios (5\% and $10 \%)$. We prepared 162 cylindrical concrete specimens with dimensions of $10 \mathrm{~cm}$ in diameter and $20 \mathrm{~cm}$ in height and 27 prismatic specimens with cross sections measuring 25 and $50 \mathrm{~cm}$ in length, with 9 different concrete mixture proportions. A longitudinal transducer with a frequency of $54 \mathrm{kHz}$ was used to measure the ultrasonic velocities. An ANN model was developed, different ANN configurations were tested and compared to identify the best ANN model. Using this model, it was possible to assess the contribution of each input variable to the compressive strength of the tested concretes. The results indicate an excellent performance of the ANN model developed to predict compressive strength from the input parameters studied, with an average error less than $5 \%$. Together, the water-cement ratio and the percentage of metakaolin were shown to be the most influential factors for the compressive strength value predicted by the developed ANN model.
\end{abstract}

Keywords: artificial neural networks; compressive strength; concrete; nondestructive testing; properties of concrete

\section{Introduction}

In the last few years, several factors have contributed to the emergence of faster tests that enable the evaluation of concrete properties, namely, the compressive strength test. Among other factors, it should be mentioned that (1) the compressive strength test increases the use of high-strength concretes in civil engineering construction; (2) the test requires a relatively long period of time; (3) the insecurity related to the conservation conditions of the specimens in the laboratory do not satisfactorily represent the reality of the work, causing significant deviations in the concrete strength results; and (4) the destructive character of the extraction of specimens poses challenges to assessing the performance of the structure in service [1-3].

Concrete technologists have always paid special attention to the possibility of determining concrete properties through nondestructive tests. According to Rose [4], the development of the ultrasonic wave propagation method started simultaneously in Canada and England in the early 1970s. In particular, ultrasound is a truly nondestructive test, as its technique involves the propagation of ultrasonic waves that do not result in any damage to the element being tested. Traditionally, the pressure wave ( $p$-wave) pulse velocity has been popularly applied to concrete structures for its easy generation and measurement. 
However, in the last few years, several studies have shown that the use of ultrasonic wave propagation tests (UPV) constitutes a promising tool for evaluating the behavior of concrete in fire situations [5,6]. In concrete structures, as described by the authors of $[5,7]$, the method can be used to (1) estimate the concrete compressive strength, (2) determine the dynamic modulus of the material, (3) evaluate the concrete homogeneity, and (4) detect the presence of cracks.

UPV testing is one of the most popular nondestructive techniques used in the assessment of concrete properties. However, a number of factors, which do not necessarily influence the concrete compressive strength in the same way, could affect the experimental UPV values. Therefore, it is very difficult to accurately evaluate the concrete compressive strength with this method. It is well known that there are a significant number of variables that influence the concrete compressive strength, such as the water-cement ratio, aggregate-cement ratio, age of testing, additions, curing time, cement types, etc. In order to associate this information, the use of artificial neural networks (ANN) is crucial, as an ANN can present a response that reflects the influence of the parameters in the obtained result $[7,8]$. In recent years, ANN modelling has become increasingly popular and has been commonly used in civil engineering tasks with some degree of success, where the modelling of material behavior and characteristics plays a significant role in these applications [9].

Metakaolin is a pozzolanic material that is basically composed of silica $\left(\mathrm{SiO}_{2}\right)$ and alumina $\left(\mathrm{Al}_{2} \mathrm{O}_{3}\right)$ in the amorphous phase. Metakaolin is capable of reacting with the calcium hydroxide $-\mathrm{Ca}(\mathrm{OH})_{2}$ - produced by cement hydration to form hydrated products that are similar to those derived from the direct hydration of the Portland clinker. This material accelerates the cement hydration process, forming additional calcium silicate (C-S$\mathrm{H}$ ) and aluminosilicate hydrates, which play an important role in the hardened concrete's properties.

Previous research has already reported trends in improving the compressive strength and durability parameters of usual- and high-strength concretes due to the use of metakaolin as a partial replacement for Portland cement [1,10-14].

The main results from the use of metakaolin in concrete mixtures reported can be summarized as follows: (1) metakaolin was shown to increase in compressive strength as the incorporation ratio of metakaolin increased at all the curing ages; (2) stabilization of the air-void structure was observed due to the high pozzolanic activity of metakaolin; (3) for improvements in compressive strength, an optimal replacement level for metakaolin close to $15 \%$ is needed by mass, which significantly enhances the resistance to chloride penetration.

\section{Research Significance}

In concrete design and quality control, compressive strength is often the most specified property. This is because, when compared to other tests used to obtain material properties, the test to determine the compressive strength is relatively easy to perform and presents a low cost. Beyond these aspects, there is a consensus in the technical-scientific community that several other concrete properties, such as the Young's modulus, tensile strength, watertightness properties, and resistance to weathering, are strongly related to the compressive strength of the material. This way, estimative values of these parameters can be obtained with enough precision for design and execution purposes from the concrete compressive strength.

The compressive strength of concrete is usually assessed by means of a standardized short-term test, which is performed at the age of 28 days to obtain the characteristic strength of the material. This value of compressive strength is the most used reference for all decision-making in the design and execution of concrete work.

Usually, the quality control tests for the concrete are performed posteriori through tests on specimens performed with the same concrete that will be used to cast a specific concrete structural element. It is, therefore, a test for the acceptability of the concrete 
received on site and not a test to assess the characteristics of the concrete already applied in a structural element.

On the other hand, some codes for the execution of concrete structures demand that the removal of molds and shoring of a structural element can only be performed when the concrete is sufficiently hardened to resist the loading applied on it and not undergo unacceptable deformations. To meet this rule, one should ensure that the mechanical properties indicated in the design drawings for a specific structural element-compressive strength, for instance-are found in that element and not in control test specimens. This is necessary because the compressive strengths in control test specimens are different than the concrete strengths in a real structural element. One possible solution for overcoming this situation is to have the concrete specimens to be tested molded in the element that was casted in order for one to have the same execution and curing conditions. This can be done, but certainly, the costs involved with the adaptation of the usual steel or timber molds used in concrete elements will be greater; this is an important issue for the concrete building industry that needs to be considered, and other strategies for meeting codes should be investigated.

Taking into account the scenario described, the research developed aimed to propose a practical approach to obtaining the concrete compressive strength of a given structural element to verify if the concrete in this element met the design demands, as a function of the main parameters used in the concrete and the ultrasonic pulse velocity, measured in the field in the element under investigation. With the aid of an ANN model, a prediction of the actual concrete compressive strength can be obtained, and the decision to remove shoring at a given age can be made.

\section{Materials and Methods}

The experimental program performed included the fabrication of a wide range of prismatic concrete specimens with dimensions of $25 \times 25 \times 50 \mathrm{~cm}^{3}$ as well as the preparation of standard cylindrical specimens-with a height of $20 \mathrm{~cm}$ and diameter of $10 \mathrm{~cm}$-made with nine different concrete mixtures.

The tests were performed at different ages, and the concrete ones were made with some previously defined parameters: the maximum size of the coarse aggregate, the amount of cement replaced by metakaolin and the water/cement ratio. To meet RILEM (Réunion Internationale des Laboratoires et Experts des Matériaux, systèmes de construction et ouvrages) recommendations, the ultrasonic transducer frequency was limited to $54 \mathrm{kHz}$, and for this reason, it was necessary to prepare concrete prisms with the crosssection size described above to ensure that the dimension perpendicular to the ultrasonic wavelength was not less than the respective wavelength $-200 \mathrm{~mm}$. For each concrete mixture, eighteen cylindrical concrete specimens were prepared for the compressive strength tests, six specimens for each age investigated $-7,28$ and 60 days.

Ultrasonic pulse velocity (UPV) tests were performed in twenty-seven concrete prisms - three prisms for each concrete mixture studied - at the same ages for each concrete mixture. For the preparation of the concrete samples studied - the prisms and cylindrical ones - the following materials were used (see Table 1 and Figure 1):

- Portland Cement CPII-F 32 with filler (90-94\% clinker and 10-6\% lime filler), with a compressive strength class of $32 \mathrm{MPa}$ and a bulk density of $3110 \mathrm{~kg} / \mathrm{m}^{3}$.

- Coarse aggregates (CA) with maximum sizes of $12.5,16.0$ and $19.0 \mathrm{~mm}$ and a bulk density of $2684 \mathrm{~kg} / \mathrm{m}^{3}$ (Table 2 shows the granulometric results).

- Fine aggregates (FA) with a bulk density of $2620 \mathrm{~kg} / \mathrm{m}^{3}$ (Table 2 shows the granulometric results). The sand used was acquired in the Metropolitan Region of Recife, and all the tests were carried out in the Laboratory of Construction Materials of the Catholic University of Pernambuco-TECOMAT, Recife, Brazil.

- Additive: poly-functional super-plasticizer (TEC-PAST-100P) with a bulk density of $1135 \mathrm{~kg} / \mathrm{m}^{3}$. 
- Metakaolin: metakaolin is a highly reactive pozzolan, consisting basically of silica $\left(\mathrm{SiO}_{2}\right)$ - and alumina $\left(\mathrm{Al}_{2} \mathrm{O}_{3}\right)$-based compounds in the amorphous phase, which combine with the calcium hydroxide- $\mathrm{Ca}(\mathrm{OH})_{2}$-which significantly improves many features of most cement-based products.

- Water.

Table 1. Mixture proportions of the specimens tested.

\begin{tabular}{|c|c|c|c|c|c|c|c|c|c|c|}
\hline \multirow[b]{2}{*}{ Mix } & \multirow{2}{*}{$\begin{array}{l}\text { Cement } \\
\left(\mathrm{kg} / \mathrm{m}^{3}\right)\end{array}$} & \multirow{2}{*}{$\begin{array}{c}\text { Sand } \\
\left(\mathrm{kg} / \mathrm{m}^{3}\right)\end{array}$} & \multicolumn{4}{|c|}{ Coarse Aggregate $\left(\mathrm{kg} / \mathrm{m}^{3}\right)$} & \multirow{2}{*}{$\begin{array}{c}\text { Additive } \\
\left(\mathrm{kg} / \mathrm{m}^{3}\right)\end{array}$} & \multirow{2}{*}{$\begin{array}{l}\text { Metakaolin } \\
\left(\mathrm{kg} / \mathrm{m}^{3}\right)\end{array}$} & \multirow{2}{*}{$\begin{array}{l}\text { Water } \\
\left(\mathrm{kg} / \mathrm{m}^{3}\right)\end{array}$} & \multirow[b]{2}{*}{ w/c } \\
\hline & & & $\begin{array}{c}\text { Gravel } \\
19\end{array}$ & $\begin{array}{c}\text { Gravel } \\
16\end{array}$ & $\begin{array}{c}\text { Gravel } \\
25\end{array}$ & $\begin{array}{c}\text { Gravel } \\
12\end{array}$ & & & & \\
\hline 1 & 471.6 & 581.5 & 768.8 & 330.1 & 0.0 & 0.0 & 2.4 & 0.0 & 217.0 & 0.46 \\
\hline 2 & 451.5 & 586.0 & 774.6 & 332.7 & 0.0 & 0.0 & 2.4 & 23.9 & 218.6 & 0.48 \\
\hline 3 & 431.0 & 590.5 & 780.6 & 335.2 & 0.0 & 0.0 & 2.4 & 47.9 & 220.3 & 0.51 \\
\hline 4 & 471.6 & 581.5 & 0.0 & 330.1 & 768.8 & 0.0 & 2.4 & 0.0 & 217.0 & 0.46 \\
\hline 5 & 451.5 & 586.0 & 0.0 & 332.7 & 774.6 & 0.0 & 2.4 & 23.9 & 218.6 & 0.48 \\
\hline 6 & 431.0 & 590.5 & 0.0 & 335.2 & 780.6 & 0.0 & 2.4 & 47.9 & 220.3 & 0.51 \\
\hline 7 & 471.6 & 581.5 & 0.0 & 0.0 & 768.8 & 330.1 & 2.4 & 0.0 & 217.0 & 0.46 \\
\hline 8 & 451.5 & 586.0 & 0.0 & 0.0 & 774.6 & 332.7 & 2.4 & 23.9 & 218.6 & 0.48 \\
\hline 9 & 431.0 & 590.5 & 0.0 & 0.0 & 780.6 & 335.2 & 2.4 & 47.9 & 220.3 & 0.51 \\
\hline
\end{tabular}
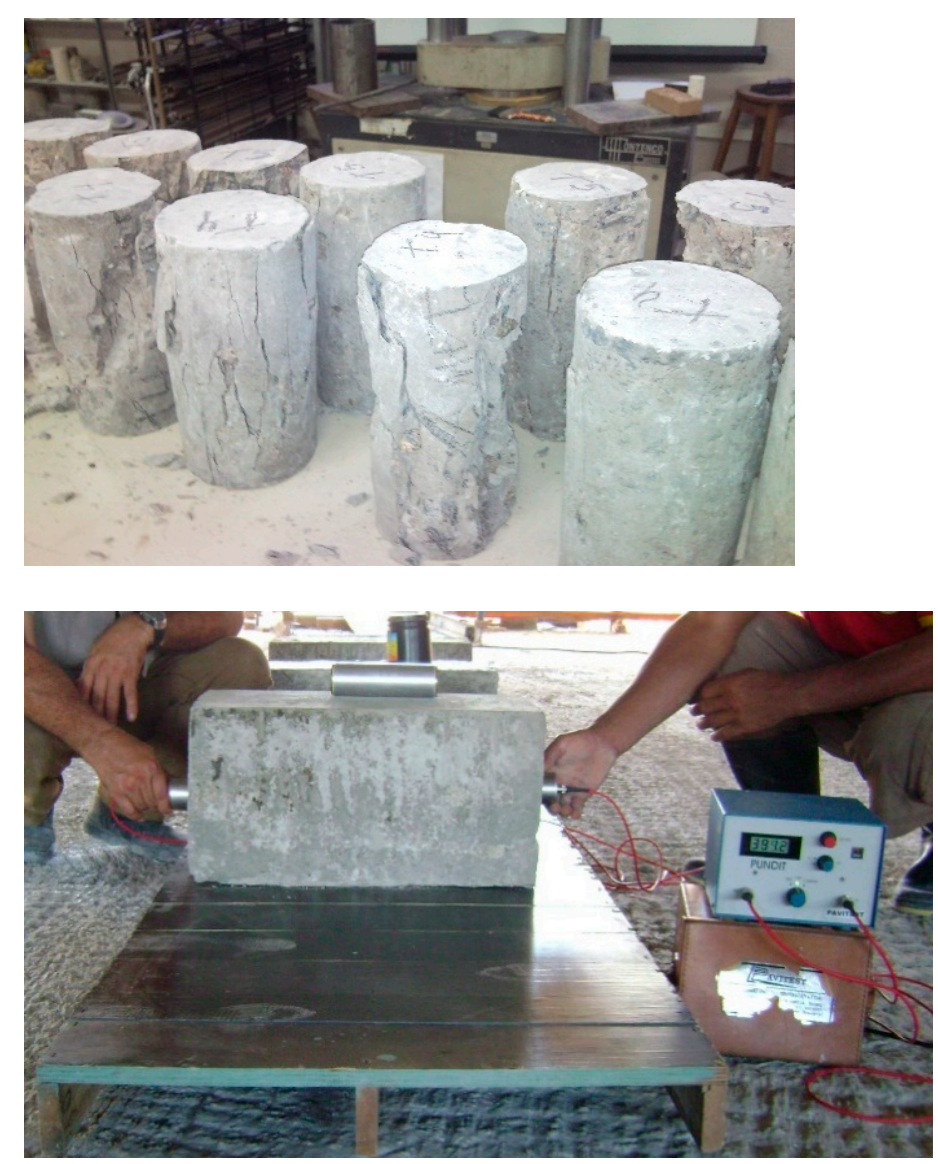

Figure 1. Specimens subjected to compressive strength tests. 
Table 2. Granulometric distribution of the aggregates used.

\begin{tabular}{cccccc}
\hline \multirow{2}{*}{$\begin{array}{c}\text { Sieves } \\
(\mathbf{m m})\end{array}$} & Gravel 19 & Gravel 16 & Gravel 25 & Gravel 12 & Sand (FA) \\
\cline { 2 - 6 } & $0.0 \%$ & $0.0 \%$ & $0.0 \%$ & $0.0 \%$ & $0.0 \%$ \\
\hline 25.0 & $75.1 \%$ & $0.0 \%$ & $51.9 \%$ & $0.0 \%$ & $0.0 \%$ \\
\hline 19.0 & $89.2 \%$ & $2.5 \%$ & $86.3 \%$ & $0.0 \%$ & $0.0 \%$ \\
\hline 16.0 & $95.9 \%$ & $59.3 \%$ & $94.1 \%$ & $0.0 \%$ & $0.0 \%$ \\
\hline 12.5 & $99.5 \%$ & $71.9 \%$ & $97.3 \%$ & $88.3 \%$ & $0.0 \%$ \\
\hline 9.5 & $100.0 \%$ & $97.1 \%$ & $99.2 \%$ & $98.9 \%$ & $0.0 \%$ \\
\hline 6.3 & $100.0 \%$ & $100.0 \%$ & $100.0 \%$ & $100.0 \%$ & $1.9 \%$ \\
\hline 4.75 & $100.0 \%$ & $100.0 \%$ & $100.0 \%$ & $100.0 \%$ & $14.6 \%$ \\
\hline 2.36 & $100.0 \%$ & $100.0 \%$ & $100.0 \%$ & $100.0 \%$ & $29.1 \%$ \\
\hline 1.18 & $100.0 \%$ & $100.0 \%$ & $100.0 \%$ & $100.0 \%$ & $44.2 \%$ \\
\hline 0.6 & $100.0 \%$ & $100.0 \%$ & $100.0 \%$ & $100.0 \%$ & $64.9 \%$ \\
\hline 0.3 & $100.0 \%$ & $100.0 \%$ & $100.0 \%$ & $100.0 \%$ & $83.6 \%$ \\
\hline 0.15 & $100.0 \%$ & $100.0 \%$ & $100.0 \%$ & $100.0 \%$ & $93.6 \%$ \\
\hline 0.075 & $100.0 \%$ & $6.43 \%$ & $100.0 \%$ & $100.0 \%$ & $100.0 \%$ \\
\hline$<0.075$ & 6.97 & 6.88 & 7.52 & 6.61 & 2.38 \\
\hline $\begin{array}{c}\text { Fineness } \\
\text { modulus (-) }\end{array}$ & & & & & \\
\hline
\end{tabular}

The specimens tested were wet-cured for 28 days after being kept in ambient conditions for 1 day. To allow the installation of transducers, lateral cuts were made, creating parallel plane surfaces diametrically opposed.

In this work, 162 cylindrical concrete test specimens and 27 prismatic specimens were made with nine different concrete mixtures. Eighteen specimens of each mixture were made and divided into three groups of six units. Each group of six was subjected to compression rupture tests according to the different ages: seven, twenty-eight and sixty days. At the same ages, each group of three prisms was subjected to nondestructive ultrasound tests. Nine readings at each age resulted in 486 ultrasonic pulse velocities.

For structuring the neural network models, input data were ordered by associating the ultrasonic velocity in the prisms with the results for the concrete test specimen's compressive strength. At each age, the average of nine ultrasonic velocities of each of the three prisms of each concrete mixture was calculated. For the six specimens at each age, three averages of two specimens were, then, calculated. Each average of nine ultrasonic velocities was associated with the average of two results of compressive tests at each. Therefore, from the treatment carried out, three input pairs per age for each concrete mixture were obtained, totaling, for the three ages and nine mixtures investigated, 81 epochs for the ANN models.

\section{Results}

The factors that affect the ultrasonic pulse velocity (UPV) can be divided into two categories:

(a) Factors resulting directly from concrete properties, such as the (1) aggregate sizing, grading, type and content; (2) cement type; (3) water/cement ratio; (4) admixtures; and (5) age of the concrete.

(b) Other factors, such as the (1) transducer contact, (2) temperature of the concrete, (3) moisture and curing conditions for the concrete, (4) path length, (5) size and shape of the specimens, (6) level of stress, and (7) presence of reinforcing steel. 


\subsection{Relationship between Compressive Strength and UPV}

There is not a clear consensus for the relationship between the compressive strength and the UPV; for example, Güneyli et al. [15] and Silva et al. [16] presented a linear relationship between these variables, and several researchers $[17,18]$ have presented an exponential relationship between compressive strength and UPV, i.e., $f_{c}=a V_{p}^{b}$ and $f_{c}=a e^{a V_{p}}$, respectively. To verify if the results for the samples investigated followed the same trend, exponential fittings between the UPV and compressive strength of the tested specimens were performed, and Figure 2 presents the best one obtained with a strong correlation coefficient (R), i.e., close to $97 \%$.

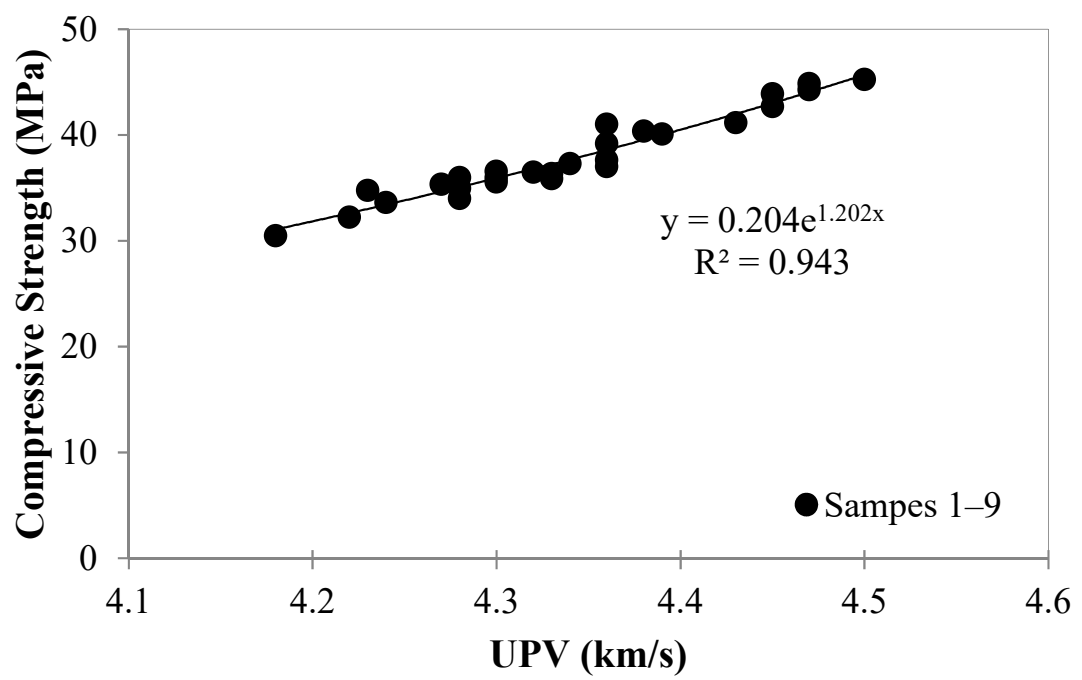

Figure 2. UPV (longitudinal) vs. compressive strength.

Table 3 presents the experimental average results for the compressive strength and ultrasonic pulse velocities obtained for each concrete mixture tested. It can be seen that for each age investigated, an increase in the metakaolin amount acted positively to increase both the compressive strength and ultrasonic pulse velocity, a fact that can be explained due to the high pozzolanic activity of metakaolin. The addition of $10 \%$ metakaolin showed it to be the best amount of cement replacement, giving the best values of compressive strength and ultrasonic pulse velocities, a result that is consistent with previous studies $[10,11]$. 
Table 3. Experimental average results for the compressive strength and ultrasonic pulse velocities (UPVs) of each mixture tested for hardened concrete specimens.

\begin{tabular}{|c|c|c|c|c|c|c|c|c|}
\hline \multirow{2}{*}{ Mixture } & \multirow{2}{*}{$\begin{array}{l}\text { Slump } \\
(\mathrm{cm})\end{array}$} & \multirow{2}{*}{$\begin{array}{l}\text { Metakaolin } \\
(\%)\end{array}$} & \multicolumn{3}{|c|}{$\begin{array}{c}\text { Compressive Strength } \\
\text { (MPa) }\end{array}$} & \multicolumn{3}{|c|}{$\begin{array}{l}\text { Ultrasonic Pulse Velocity, UPV } \\
(\mathbf{k m} / \mathrm{s})\end{array}$} \\
\hline & & & 7 days & 28 days & 60 days & 7 days & 28 days & 60 days \\
\hline 1 & 12 & 0 & 34.77 & 36.55 & 41.00 & 4.23 & 4.30 & 4.36 \\
\hline 2 & 19 & 5 & 34.96 & 37.27 & 43.90 & 4.28 & 4.34 & 4.45 \\
\hline 3 & 10 & 10 & 39.18 & 44.86 & 45.25 & 4.36 & 4.47 & 4.50 \\
\hline 4 & 20 & 0 & 32.24 & 35.86 & 37.00 & 4.22 & 4.33 & 4.36 \\
\hline 5 & 18 & 5 & 35.33 & 35.95 & 40.35 & 4.27 & 4.28 & 4.38 \\
\hline 6 & 10 & 10 & 37.61 & 42.67 & 44.26 & 4.36 & 4.45 & 4.47 \\
\hline 7 & 18 & 0 & 30.47 & 34.00 & 35.56 & 4.18 & 4.28 & 4.30 \\
\hline 8 & 18 & 5 & 33.60 & 35.95 & 36.47 & 4.24 & 4.30 & 4.32 \\
\hline 9 & 17 & 10 & 36.33 & 40.09 & 41.15 & 4.33 & 4.39 & 4.43 \\
\hline
\end{tabular}

\subsection{Influence of Metakaolin and Aggregate on Concrete Compressive Strength}

Regarding the diameter of the aggregates, it can be said that the mixtures that showed greater compressive strength were those with $19 \mathrm{~mm}$ coarse aggregate sizes, granulometrically improved compared to those with $16 \mathrm{~mm}$ coarse aggregate sizes. Likewise, this mixture was also consistent with regard to the increase in strength related to the amount of metakaolin. In fact, metakaolin is a highly reactive pozzolan that significantly improves many features of most cement-based products in the short and long term [19].

Some authors $[16,20,21]$ report that with a $5 \%$ addition of metakaolin, it is already possible to observe an increase of 12 to $15 \%$ in concrete compressive strength, and for an addition of $10 \%$, the observed increase in strength varied from 9 to $28 \%$ [22,23]. It is important to highlight that it is well known that the aggregate size influences the Young's modulus of concrete more than its compressive strength [24], although compressive strength might also be related to concrete pore size composition-distribution and spacing [25]. Decreasing the coarse aggregate size can also increase the concrete compressive strength [26-28], mainly due to the increase in adherence generated by the effect of aggregate size reduction [27-29].

The fact that concretes made with coarse aggregate size combinations-19 and $16 \mathrm{~mm}-$ presented better performance than the mixtures made with 25 and $16 \mathrm{~mm}$ aggregate sizes and the mixture made with 25 and $12 \mathrm{~mm}$ aggregate sizes shows the importance of improved granulometry in the performance of concretes.

It can be said that, for the mixtures investigated in this work and their respective materials, the granulometric improvement with $16 \mathrm{~mm}$ coarse aggregate was better realized when the coarse aggregate used was $19 \mathrm{~mm}$ in size. This happens because it creates a condition that is close to the packaging process in concrete manufacture. The combination of 25 and $12 \mathrm{~mm}$ aggregate sizes presented a greater number of voids to be filled, directly reflecting the value of the compressive strength.

It was also found that the addition of metakaolin exhibited a greater effect in increasing the compressive strength at the ages of 28 and 60 days. The most significant evolution in compression occurred until the seventh day; after this period, there was a very small increase in the compressive strength.

As shown in Figure 3, the addition of metakaolin in mixtures 3, 6 and 9 did not generate a significant influence, either on the compressive strength or on the UPV, at the age of 7 days. An opposite behavior, however, was observed at 28 and 60 days, where it was observed that, with an increase in the addition, the UPV and the compression strength presented an increase. 
As shown in Figure 4, for the same water/cement ratio, the same mortar content and the same amount of addition of metakaolin, the best combination of two coarse aggregate sizes was 16 and $19 \mathrm{~mm}$. This combination for all ages showed the greatest compressive strength and the highest ultrasonic pulse velocity.
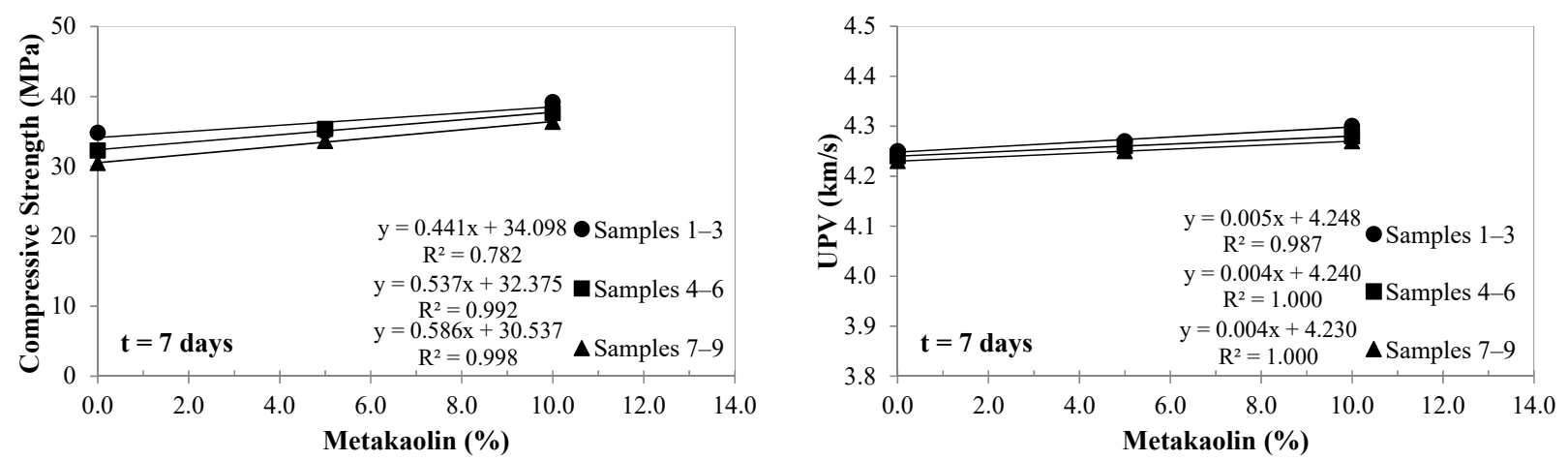

(a)
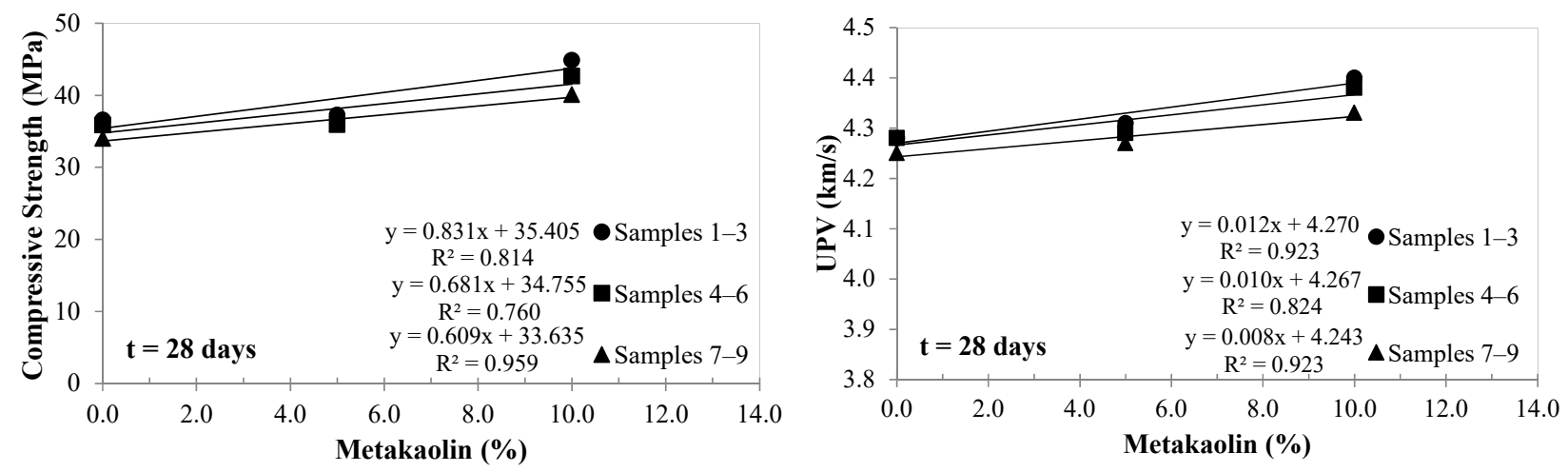

(b)
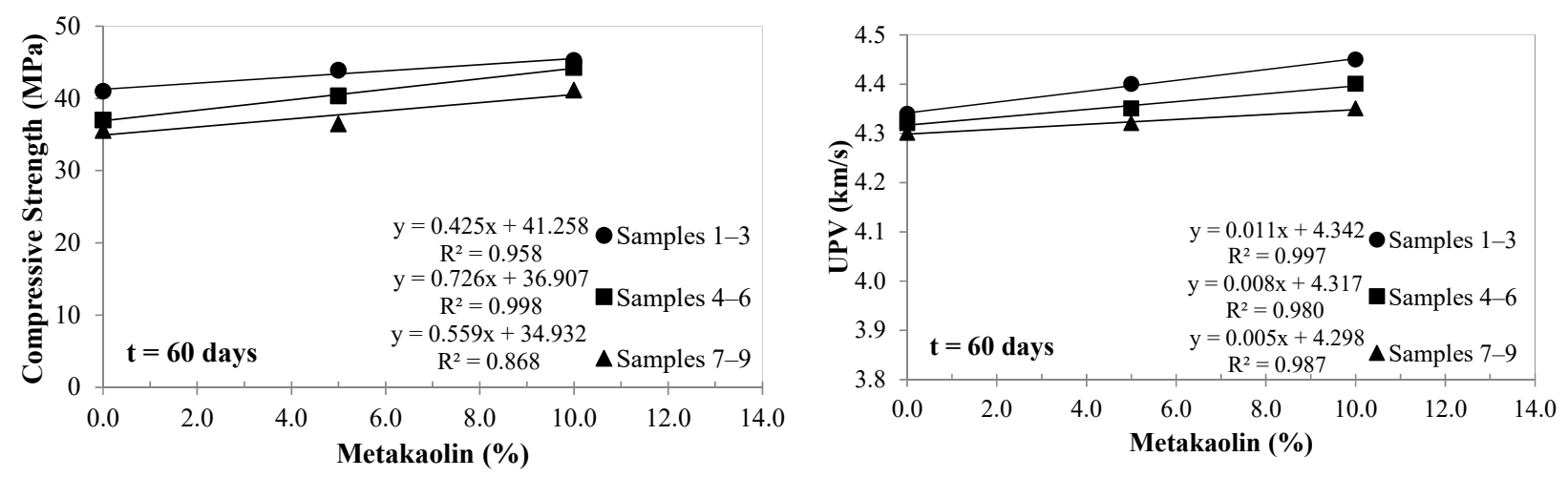

(c)

Figure 3. Influence of the metakaolin on concrete compressive strength and UPV, for (a) 7 days, (b) 28 days and (c) 60 days. 

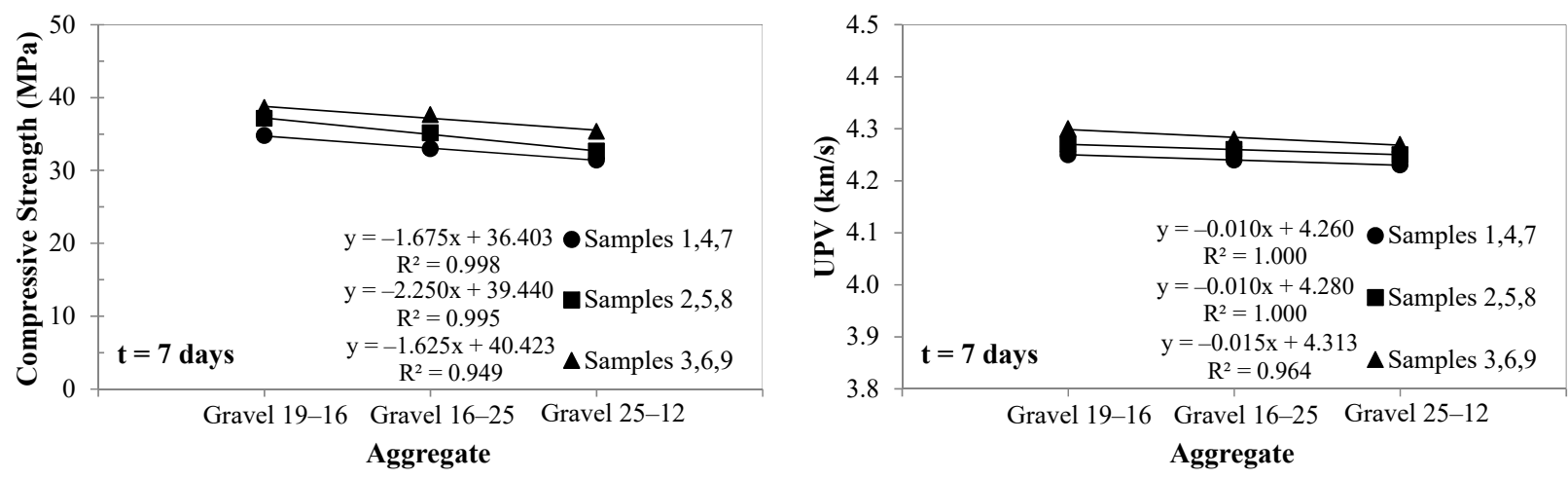

(a)
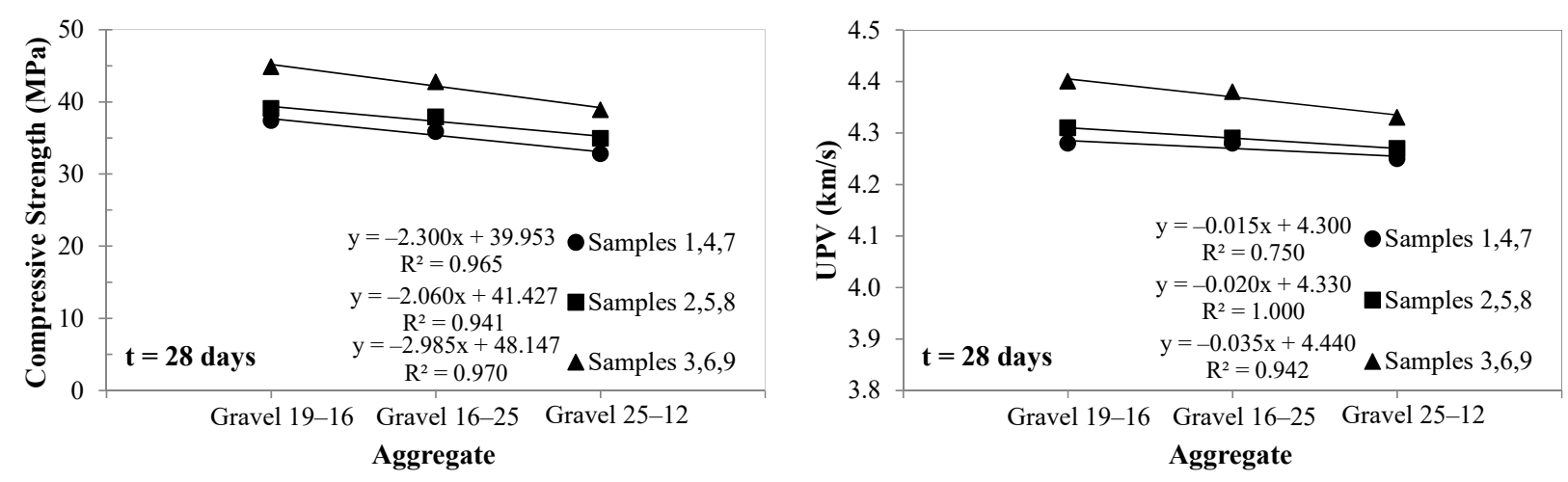

(b)
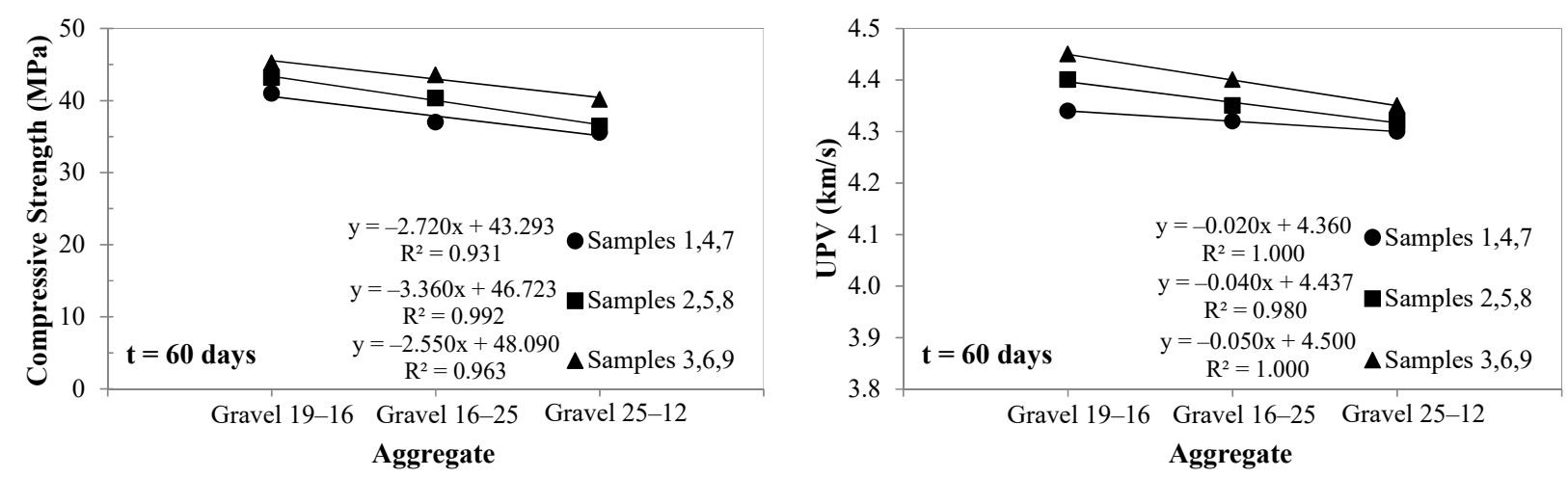

(c)

Figure 4. Influence of the aggregate on concrete compressive strength and UPV, for (a) 7 days, (b) 28 days and (c) 60 days.

\subsection{Artificial Neural Network Modelling}

Regression models based on experimental research results are commonly used strategies for the qualitative assessment of a given parameter of interest, based on variables that influence its behavior. However, depending on the field of scientific research and the phenomena under investigation, the complexity of the relationships between input and output variables may significantly limit the ability of these models to provide adequate responses. In these situations, more efficient modelling tools such as artificial neural networks can be more applicable.

Artificial neural networks use concepts associated with the massive local and distributed processing believed to occur in the human brain. These networks acquire knowl- 
edge through experience, and this knowledge is represented by the ability to map relationships between input and output parameters. A neural network is best defined as a set of simple, highly interconnected processing elements that are capable of learning information presented to them, and their ability to learn and process information classifies them as a form of artificial intelligence.

ANNs are especially useful for dealing with situations in which establishing a description of the functional relationships between the variables involved in a problem is either overly complex or impossible. The success of ANN problem modelling is directly related to the network architecture, i.e., the number of hidden layers and the number of neurons in these layers and training strategies used.

A very important task for creating an ANN model is defining its hidden layer architecture. Several studies have already shown that it is always possible to obtain a single hidden layer solution with the same level of learning of complex solutions as several hidden layers with a large number of hidden neurons [30,31].

To build concrete compressive strength prediction models through nondestructive ultrasound testing combined with the network model, the software QNET [32] was used. QNET is a multi-layer perceptron whose training is performed using a retro-propagation algorithm. This program allows the definition of up to eight intermediate layers of neurons and the choice of four different activation functions (sigmoid, tangent hyperbolic, hyperbolic and Gaussian).

Predicting the axial compression strength of concrete is a complex problem, influenced by a number of factors, mainly, the water-cement (w/c) and aggregate-cement (ag/c) ratios, testing age, and amount and type of addition, among others, and its modelling with ANNs is a hard task to implement.

To assess the potentialities for predicting the compressive strength of concrete, an ANN model using experiments described in Section 2 was created with the following features: five input variables - the water cement ratio, aggregate cement ratio, age of testing, metakaolin cement ratio, and measured ultrasonic velocity. The output variable was the average compression strength $\left(f_{c}\right)$.

For the development of models with the ANN, data normalization is necessary. This normalization is essential since the different activation functions that activate neurons in the model provide values within a range between 0 and 1 . The software used to create the ANN models allows automatic data normalization, but this normalization omits important information. For that reason, the input and output data values were normalized outside the software considering a linear relationship between the maximum and minimum values of each of the variables, within the range 0.25-0.85, using Equation (1):

$$
\frac{X_{\text {norm }}-0.25}{0.85-0.25}=\frac{X-X_{\min }}{X_{\max }-X_{\min }}
$$

where $X_{\text {norm }}$ is the normalized variable, $X$ is the variable to be normalized, $X_{\max }$ is the maximum value of the variable to be normalized and $X_{\min }$ is the minimum value of the variable to be normalized.

After data analysis and processing, the final set used in the training and validation phases totaled 81 epochs. In order to test the developed neural network models, a separation of the input data into a training group and a test group was implemented. In the research, $15 \%$ of the input data were randomly chosen to test the model while it was being trained. This means that the model was not presented to this set of data in the training phase, and in fact, the model was trained using 69 epochs. The result data were exclusively used to verify the quality of the ANN during its training process.

For the ANN models investigated, a specific strategy was used to avoid the possibility that overtraining might govern the model's response. Overtraining occurs when the test set error increases while the training set error continues to descend. This indicates that memorization is the predominant learning mode. When a test set error has reached a global minimum and increases indefinitely thereafter, overtraining has occurred. Training 
a network after the test set error global minimum has been reached can actually hurt the predictive capabilities of the model being developed.

The model elaborated in this work was developed with the objective of obtaining a good approximation for the compressive strength of concrete as a function of the water/cement ratio $(\mathrm{w} / \mathrm{c})$, aggregate/cement ratio $(\mathrm{ag} / \mathrm{c})$, testing age $(\mathrm{t})$, metakaolin/cement ratio $(\mathrm{mk} / \mathrm{c})$ and measured ultrasonic velocity $(\mathrm{V})$ represented by Equation (2):

$$
f_{c}=\mathrm{f}\left(\frac{\mathrm{a}}{\mathrm{c}}, \frac{\mathrm{ag}}{\mathrm{c}}, \mathrm{t}, \frac{\mathrm{mk}}{\mathrm{c}}, \mathrm{V}\right)
$$

After several trials, the architecture of the hidden network layers that exhibited the best error was as follows: [3-5-(1x8)-1]. That means an ANN with three layers-one input layer with five neurons representing the five input variables, one hidden layer with nine neurons, and one output layer of neurons with one neuron representing the compressive strength. Figure 5 shows the ANN architecture used for the prediction of the concrete compressive strength of the concretes studied.

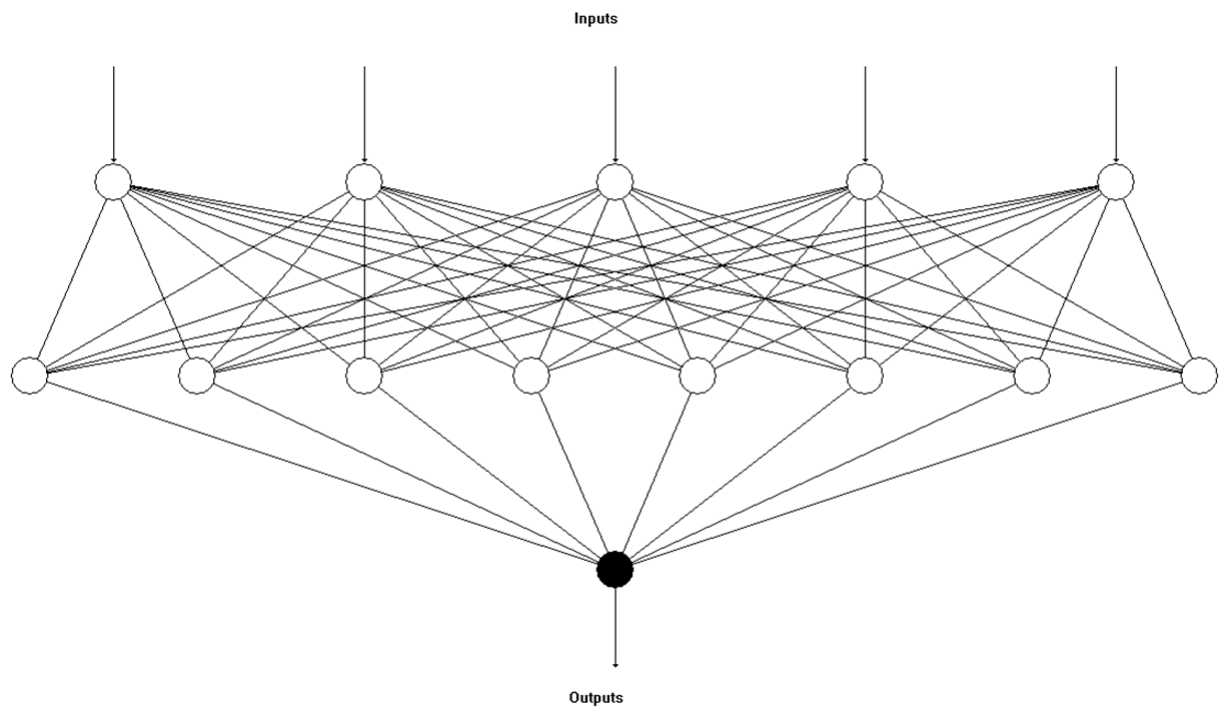

Figure 5. Final artificial neural network (ANN) architecture for predicting compressive strength of concrete.

Figure 6 shows the evolution of the correlation coefficient $R^{2}$ during the training process for the several ANN models investigated. It can be seen that the model that presented the best overall behavior was the model [3-5-(1×8)-1] — with $R^{2}$ of $95.42 \%$ and $87.24 \%$ for the training and test sets, respectively. The other models presented good performance in the training phase but not so good performance in the testing phase. 

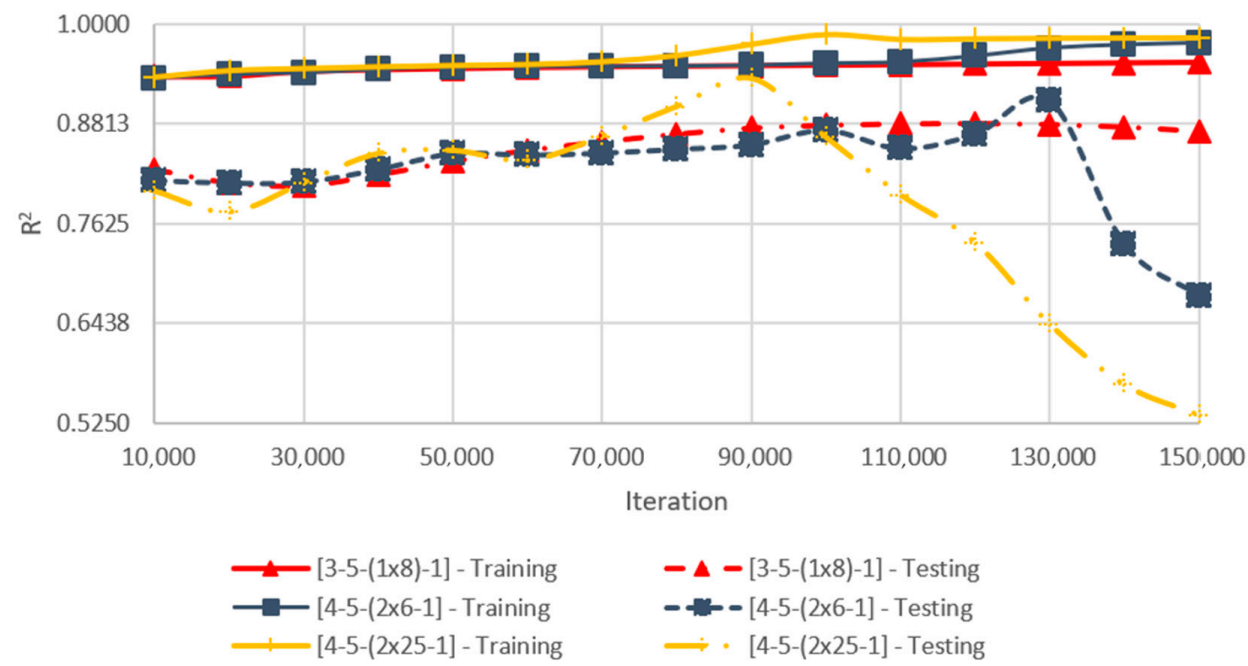

$$
\begin{aligned}
& -\boldsymbol{\Delta}-[3-5-(1 \times 8)-1] \text { - Testing } \\
& -\boldsymbol{-}-[4-5-(2 \times 6-1]-\text { Testing } \\
& \longrightarrow \cdot[4-5-(2 \times 25-1]-\text { Testing }
\end{aligned}
$$

Figure 6. Evolution of correlations with number of iterations in the training phase and validation of the final model with architecture [3-5-(1x8)-1].

A scatter comparison between the targets and network outputs-the concrete compressive strengths output by the network and the values obtained with the laboratory tests-is shown in Figure 7. A good agreement can be observed, which means that the ANN models were able to capture the complexity of the relationships among the several parameters involved in the problem.

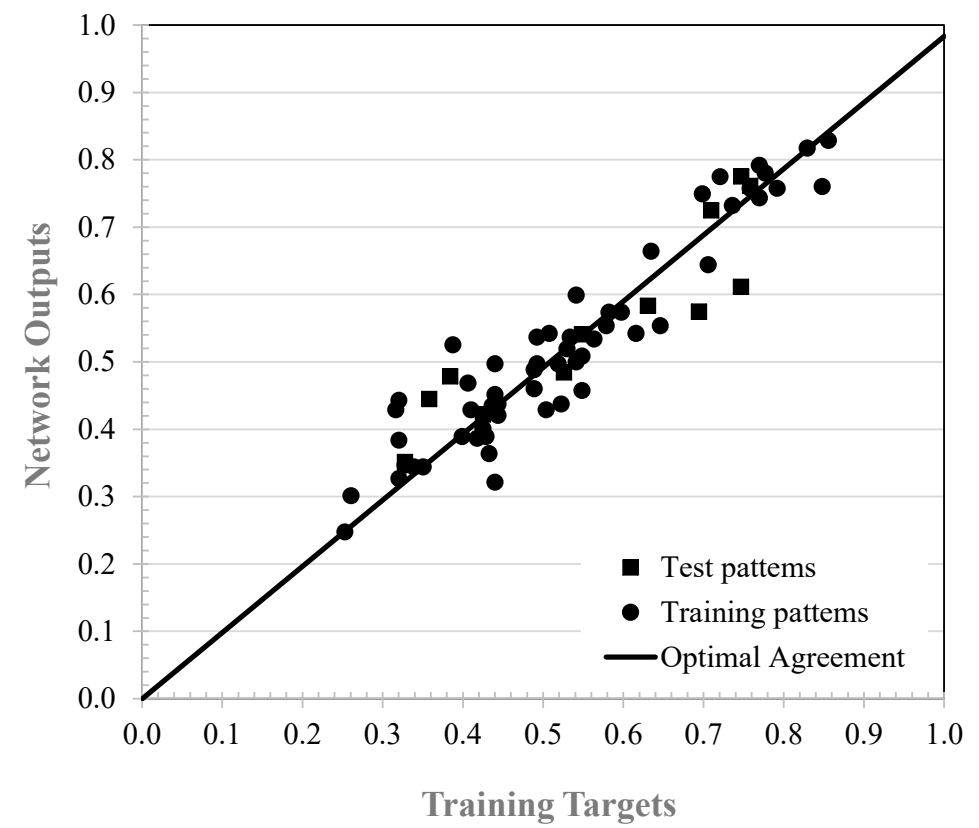

Figure 7. Scatter comparison of targets vs. network outputs.

Table 4 shows the comparison between the targets and ANN outputs, where the quality of the overall behavior of the model can be confirmed. Most of the data in Table 4 were obtained from points that were not used in net training. This means that they are unknown data for the model. In view of this observation, one can conclude that the model behaved very satisfactorily in predicting the concrete compressive strength from the input parameters studied. 
Table 4. Comparison between targets and ANN outputs.

\begin{tabular}{ccccccc}
\hline w/c & $\mathbf{a g} / \mathbf{c}$ & $\begin{array}{c}\text { Age } \\
\text { (days) }\end{array}$ & $\begin{array}{c}\mathbf{m k} / \mathbf{c} \\
\mathbf{( \% )}\end{array}$ & $\begin{array}{c}\mathbf{V} \\
(\mathbf{m} / \mathbf{s})\end{array}$ & \multicolumn{2}{c}{ Compressive Strength (MPa) } \\
\hline 0.511 & 2.589 & 60 & 10 & 4.31 & 33.18 & ANN Model \\
\hline 0.460 & 2.330 & 60 & - & 4.37 & 40.51 & 40.33 \\
\hline 0.511 & 2.589 & 60 & 10 & 4.33 & 38.33 & 39.36 \\
\hline 0.511 & 2.589 & 60 & 10 & 4.47 & 43.53 & 45.02 \\
\hline 0.484 & 2.453 & 7 & 5 & 4.28 & 34.96 & 36.21 \\
\hline 0.511 & 2.589 & 28 & 10 & 4.47 & 44.82 & 44.13 \\
\hline 0.484 & 2.453 & 28 & 5 & 4.35 & 37.77 & 38.14 \\
\hline 0.460 & 2.330 & 7 & - & 4.22 & 32.24 & 34.73 \\
\hline 0.460 & 2.330 & 28 & - & 4.40 & 39.61 & 40.23 \\
\hline 0.511 & 2.589 & 28 & 10 & 4.25 & 35.33 & 36.29 \\
\hline 0.484 & 2.453 & 60 & 5 & 4.28 & 32.09 & 35.41 \\
\hline 0.460 & 2.330 & 28 & - & 4.33 & 35.31 & 37.95 \\
\hline 0.460 & 2.33 & 7 & - & 4.25 & 35.18 & 35.10 \\
\hline 0.511 & 2.589 & 28 & 10 & 4.46 & 42.29 & 44.01 \\
\hline 0.484 & 2.453 & 28 & 5 & 4.26 & 37.48 & 36.30 \\
\hline 0.511 & 2.589 & 60 & 10 & 4.52 & 45.81 & 45.39 \\
\hline 0.511 & 2.589 & 7 & 10 & 4.49 & 43.27 & 43.62 \\
\hline 0.460 & 2.330 & 28 & - & 4.40 & 39.61 & 40.23 \\
\hline 0.460 & 2.330 & 7 & - & 4.28 & 34.87 & 35.41 \\
\hline 0.484 & 2.453 & 28 & 5 & 4.31 & 38.22 & 37.69 \\
\hline & & 7 & & & & \\
\hline
\end{tabular}

In order to investigate the influence of each input parameter on the concrete compressive strength prediction result, Table 5 was prepared. From this table, it is possible to observe that, for the concretes mixtures studied, with the exception of the testing age, the other parameters investigated showed a similar contribution in the results of the neural network model. The fact that age did not show significant importance is consistent with expectations because the concrete mixtures studied had moderate compressive strength and their evolution over time should not have been so marked for the ages studied. The water-cement ratio and the percentage of metakaolin together showed an influence of more than $50 \%$, which is equally consistent.

Table 5. Contribution of input node to outputs.

\begin{tabular}{cc}
\hline Input Node & Contribution (\%) \\
\hline $\mathrm{w} / \mathrm{c}$ & 26.0 \\
\hline $\mathrm{ag} / \mathrm{c}$ & 22.9 \\
\hline $\mathrm{t}$ & 5.6 \\
\hline $\mathrm{mk} / \mathrm{c}$ & 26.3 \\
\hline $\mathrm{V}$ & 19.2 \\
\hline
\end{tabular}

\section{Conclusions}

The research performed was successful in proving that ANN modelling is a good strategy for predicting the compressive strength of concrete using special information about the concrete mixture and its ultrasonic pulse velocity. Good correlation coefficients 
were obtained for the trained nets, an aspect that highlights the applicability of the developed models.

The great benefit in using artificial neural networks to solve engineering problems lies in the fact that these models can be "trained" to learn the existing relationships between the input and output parameters of a given problem. This characteristic has great importance when dealing with situations in which the establishment of a description of the functional relationships between the variables involved in a given problem is either excessively complex or simply not possible. On the other hand, an important difficulty in using neural networks to solve engineering problems lies in the difficulty in establishing an adequate internal architecture for the problem being addressed. In the present work, this difficulty was overcome by adopting a simultaneous training and validation strategy that allowed the rapid identification of the best architecture for the studied problem.

A secondary result of this research is that the ANN model was able to capture the influence of the concrete mixture parameters used in the investigation that played a more important role in the compressive strength of the concrete-the water/cement ratio $(\mathrm{w} / \mathrm{c})$, aggregate/cement ratio (ag/c) and metakaolin/cement ratio $(\mathrm{mk} / \mathrm{c})$ - which together contributed about $75 \%$ to the end result for the concrete compressive strength.

The ultrasonic pulse velocities also showed an important participation in the compressive strength of concrete, with approximately $20 \%$ contribution, but they were not the most important factor. This fact suggests that the equations available in the literature that seek to correlate the compressive strength of concrete with only with its ultrasonic velocity need to be adjusted to consider other parameters related to the concrete mixture, although the relationship between the UPV and compressive strength was demonstrated to be strong and linear, following the literature.

Author Contributions: All the authors contributed to the development, analysis, writing, and revision of the paper: conceptualization, F.A.N.S., R.S.C. and J.M.P.Q.D.; methodology, F.A.N.S., J.M.P.Q.D., R.S.C. and A.C.A.; software, F.A.N.S.; validation, A.C.A., A.S.G. and A.G.B.L.; formal analysis, A.C.A., A.S.G., J.M.P.Q.D. and A.G.B.L.; investigation, R.S.C., F.A.N.S.; writing—original draft preparation, F.A.N.S., A.S.G., J.M.P.Q.D., A.C.A. and A.G.B.L.; writing-review and editing, R.S.C., A.S.G., J.M.P.Q.D. and A.G.B.L.; supervision, F.A.N.S., J.M.P.Q.D. and A.G.B.L. All authors have read and agreed to the published version of the manuscript.

Funding: This work was supported by Base Funding-UIDB/04708/2020 and Programmatic Funding-UIDP/04708/2020 of the CONSTRUCT-Instituto de I\&D em Estruturas e Construções-funded by national funds through the FCT/MCTES (PIDDAC).

Institutional Review Board Statement: Not applicable.

Informed Consent Statement: Not applicable.

Data Availability Statement: New data were created or analyzed in this study. Data will be shared upon request and consideration of the authors.

Conflicts of Interest: The authors declare no conflict of interest.

\section{References}

1. El-Din, H.K.S.; Eisa, A.S.; Aziz, B.H.A.; Ibrahim, A. Mechanical performance of high strength concrete made from high volume of Metakaolin and hybrid fibers. Constr. Build. Mater. 2017, 140, 203-209. [CrossRef]

2. Dinakar, P.; Sahoo, P.K.; Sriram, G. Effect of metakaolin content on the properties of high strength concrete. Int. J. Concr. Struct. Mater. 2013, 7, 215-223. [CrossRef]

3. Ray, I.; Gong, Z.; Davalos, J.F.; Kar, A. Shrinkage and cracking studies of high performance concrete for bridge decks. Constr. Build. Mater. 2012, 28, 244-254. [CrossRef]

4. Rose, J.L. Ultrasonic Waves in Solid Media; Cambridge University Press: Cambridge, UK, 1990.

5. Malhotra, V.M.; Carino, N.J. HandBook on Nondestructive Testing of Concrete, 2nd ed.; CRC Press: Boca Raton, FL, USA, 2004.

6. Balaji, K.V.G.D.; Raju, S.S.S.V.G. Nondestructive assessment of concrete structures exposed to fire. Int. J. Appl. Environ. Sci. 2009, 4, 25-31.

7. Güçlüer, K. Investigation of the effects of aggregate textural properties on compressive strength (CS) and ultrasonic pulse velocity (UPV) of concrete. J. Build. Eng. 2020, 27, 100949. [CrossRef] 
8. Mohamed, O.A.; Ati, M.; Hawat, W. Implementation of artificial neural networks for prediction of chloride penetration in concrete. Int. J. Eng. Technol. 2018, 7, 47-52. [CrossRef]

9. Bilgehan, M.A. comparative study for the concrete compressive strength estimation using neural network and neuro-fuzzy modelling approaches. Nondestruct. Test. Eval. 2011, 26, 35-55. [CrossRef]

10. Dinakar, P. The effect of Metakaolin on high strength concrete. J. Mater. Sci. 2013, 9, 379-382.

11. Supit, S.W.M.; Pandei, R.W. Effects of Metakaolin on Compressive Strength and Permeability Properties of Pervious Cement Concrete. J. Teknol. 2019, 81, 33-39.

12. Poon, C.S.; Lam, L.; Kou, S.C.; Wong, Y.L.; Wong, R. Rate of Pozzolanic Reaction of Metakaolin in High Performance Cement Pastes. Cem. Concr. Res. 2001, 39, 1301-1306. [CrossRef]

13. Egwuonwu, W.C.; Akobo, I.Z.S.; Ngekpe, B.E. Effect of Metakaolin as a Partial Replacement for Cement on the Compressive Strength of High Strength Concrete at Varying Water/Binder Ratios. Int. J. Civ. Eng. 2019, 6, 1-6.

14. Ramezanicanpour, A.A.; Bahrami, J.H. Influence of Metakaolin as Supplementary Cementing Material on Strength and Durability of Concretes. Constr. Build. Mater. 2012, 30, 470-479. [CrossRef]

15. Güneyli, H.; Karahan, S.; Güneyli, A.; Yapıcı, N. Water content and temperature effect on ultrasonic pulse velocity of concrete. Russ. J. Nondestruct. Test. 2017, 53, 159-166. [CrossRef]

16. Silva, F.A.N.; Nogueira, C.L.; Silva, J.A.; Azevedo, A.C.; Delgado, J.M.P.Q. Ultrasonic Assessment of Damage in Concrete under Compressive and Thermal Loading Using Longitudinal and Transverse Waves. Russ. J. Nondestruct. Test. 2019, 55, 808-816. [CrossRef]

17. Tharmaratnam, K.; Tan, B.S. Attenuation of ultrasonic pulse in cement mortar. Cem. Concr. Res. 1990, 20, 335-345. [CrossRef]

18. Musmar, M.A.; Alhadi, N.A. Relationship between ultrasonic pulse velocity and standard concrete cube crushing strength. J. Eng. Sci. 2008, 36, 51-59. [CrossRef]

19. Salimi, J.; Ramezanianpour, A.M.; Moradi, M.J. Studying the effect of low reactivity metakaolin on free and restrained shrinkage of high performance concrete. J. Build. Eng. 2020, 28, 101053. [CrossRef]

20. Güneisi, E.; Gesoglu, M.; Mermerda, K. Improving strength, drying shrinkage, and pore structure of concrete using metakaolin. Mater. Struct. 2008, 41, 937-949. [CrossRef]

21. Muthupriya, P.; Subramanian, K.; Vishnuram, B.G. Investigation on behaviour of high performance reinforced concrete columns with metakaolin and fly ash as admixture. Int. J. Adv. Eng. Technol. 2011, 2, 190-202.

22. Madandoust, R.; Mousavi, S.Y. Fresh and hardened properties of self-compacting concrete containing metakaolin. Constr. Build. Mater. 2012, 35, 752-760. [CrossRef]

23. Kirthini, C.H.; Sujatha, T. Effect of incorporating metakaolin on the properties of high performance concrete. Int. J. Eng. Res. Technol. 2014, 3, 1011-1014.

24. Güneyisi, E.; Gesoğlu, M.; Karaoğlu, S.; Mermerdaş, K. Strength, permeability and shrinkage cracking of silica fume and metakaolin concretes. Constr. Build. Mater. 2012, 34, 120-130. [CrossRef]

25. Deo, O.; Neithalath, N. Compressive behavior of pervious concretes and a quantification of the influence of random pore structure features. Mater. Sci. Eng. A 2010, 528, 402-412. [CrossRef]

26. Agar-Ozbek, A.S.; Weerheijm, J.; Schlangen, E.; van Breugel, K. Investigating porous concrete with improved strength: Testing at different scales. Constr. Build. Mater. 2013, 41, 480-490. [CrossRef]

27. Zhong, R.; Wille, K. Compression response of normal and high strength pervious concrete. Construct. Build. Mater. 2016, 109, 177-187. [CrossRef]

28. Sun, Z.; Lin, X.; Vollpracht, A. Pervious concrete made of alkali activated slag and geopolymers. Constr. Build. Mater. 2018, 189, 797-803. [CrossRef]

29. Xu, G.; Shen, W.; Huo, X.; Yang, Z.; Wang, J.; Zhang, W.; Ji, X. Investigation on the properties of porous concrete as road base material. Constr. Build. Mater. 2018, 158, 141-148. [CrossRef]

30. Beale, R.; Jackson, T. Neural Computing, 2nd ed.; Bristol, Hilger, IOP (Institute of Physics) Publication: Bristol, UK, 1992.

31. Hecht-Nielsen, R. Neurocomputying; Addison-Wesley Longman Publishing Co., Inc.: Boston, MA, USA, 1989.

32. QNET. Qnet 2000 Shareware; Vesta Services, Inc.: Winnetka, IL, USA, 2000. 